\title{
Real Time Implementation of Series Expansion Based Digital Controller for Magnetic Levitation System
}

\author{
Avadh Pati ${ }^{*}$, Vijay Kumar Verma ${ }^{2}$, Richa Negi ${ }^{1}$, Shyam Krishna Nagar ${ }^{3}$ \\ ${ }^{1}$ Department of Electrical Engineering, Motilal Nehru National Institute of Technology, Allahabad, India \\ ${ }^{2}$ School of Electronics Engineering, Kalinga Institute of Industrial Technology, Bhubaneswar, India \\ ${ }^{3}$ Department of Electrical Engineering, Indian Institute of Technology BHU, Varanasi, India \\ Email: *er.avadhmnnit@gmail.com, vijay.vermafet@kiit.ac.in, richa@mnnit.ac.in, sknagar@bhu.ac.in
}

How to cite this paper: Pati, A., Verma, V.K., Negi, R. and Nagar, S.K. (2016) Real Time Implementation of Series Expansion Based Digital Controller for Magnetic Levitation System. Intelligent Control and $\mathrm{Au}$ tomation, 7, 110-128.

http://dx.doi.org/10.4236/ica.2016.74011

Received: October 7, 2016

Accepted: November 12, 2016

Published: November 15, 2016

Copyright $\odot 2016$ by authors and Scientific Research Publishing Inc. This work is licensed under the Creative Commons Attribution International License (CC BY 4.0).

http://creativecommons.org/licenses/by/4.0/ (c) (i) Open Access

\begin{abstract}
This paper addresses a digital controller for a real time magnetic levitation system using series expansion of pulse transfer function, which achieves desired closed loop response. The proposed digital controller designed, based on series expansion of pulse transfer function by solving a linear equation using the method of least squares, which improves the transient performance and step tracking capability of the compensated system. The designed algorithm used for the control input is not iterative, so the calculation is very fast. The proposed control scheme has successfully applied on maglev system and also validated through the simulation and hardware experimental results.
\end{abstract}

\section{Keywords}

Maglev System, Least Squares, Series Expansion, Pulse Transfer Function, Digital Controller

\section{Introduction}

Magnetic Levitation technology has received tremendous innovation in various engineering fields and is being utilized in various automation applications [1] [2]. The concept behind all applications is to provide contactless levitation to reduce the effect of wear and tear, therefore, increasing the efficiency and reliability. These days, this technology has covered major applications in different areas like transportation field, maglev trains [3] [4] [5] [6], personal rapid transit, defence area (gun, rocketry), nuclear engineering (the centrifuge of nuclear reactor), chemical engineering [7] (for analyzing 
foods and beverages), architectural and interior design (lamp, chair, sofa, bed, washing machine), biomedical field (heart pump) [8] [9] [10], civil engineering [11]-[18] (magnetic bearing, elevator, lift, fan, compressor, chillers, pump and geothermal heat pumps) etc.

The magnetic levitation system is nonlinear and unstable. There are various control strategies [19] [20] available for their stable operation. Some control schemes are applied on the linearized model of magnetic levitation system and some of controllers are implemented in nonlinear environment [21]. The most common controller used is PID due to its simple construction and easy implementation. Nowadays, some extended versions of PID controllers are reported in literature such as FOPID controller [22] [23] [24] in which five tunable parameters (only three tunable parameters available in conventional PID controller) are considered and providing more flexibility for design. Fuzzy PID controller [25] [26] [27] [28] is designed with the help of expert knowledge considering the parameter uncertainties. In [28], an Interval Type-2 Fuzzy PID control scheme is suggested for controlling of maglev system and SMC based fuzzy controller is used to minimize the effect of parameter uncertainty and disturbance [29]. In [30], 2-DOF PID controller has been designed for magnetic levitation system to achieve the desired speed of response and tuning of PID parameters is calculated by using pole placement technique for desired damping ratio and settling time with two adjustable gains. An integral variable structure grey control [31] has been applied on SMC to overcome the chattering present in the scheme for the expected limit of uncertainties and disturbances. An adaptive robust output feedback controller [32] is designed by using backstepping approach with robustifying modification of the K-filter scheme to avoid the noise present in the sensor at the output for proper tracking of position of magnetic levitation system. H-infinity based control scheme is discussed in [33] [34]. In [34], $\mathrm{H} \infty$ controller is designed to achieve the set-point regulation and disturbance attenuation. Robust dynamic sliding mode control has been designed to control the position of magnetically suspended metallic object in presence of uncertainties and nonlinear term is estimated using RENN estimator [35] [36] [37]. Fuzzy compensation based adaptive PID controller is reported in [38] in which adaptive PID is main controller and their parameters are tuned by adaptive law and Fuzzy compensation controller is designed for obtaining the guaranteed stability.

The major finding from the above existing control strategies is that, the transient response (settling time and peak overshoots) of magnetic levitation system is not up to mark. Digital control provides flexibility and easy implementation of wide range of control algorithms over there analog counter parts and also achieves deadbeat response [39] [40] [41]. Motivated from this philosophy, single loop digital controller is designed using series expansion of pulse transfer function in [42] and a modified digital controller is designed for double loop system in [43]. Gain scheduling method based digital control scheme is used to tune the parameters of power MOSFET or board impedance between each phase for optimization in current balance [44].

Looking into the advantages of digital control, the present work proposes a control 
scheme for magnetic levitation system, which is based on series expansion of pulse transfer function [42] [43] that provides better transient response, fast dynamic response and also could be implemented in digital environment directly. To the best of authors' knowledge, this digital control technique based on series expansion has not been applied so far on the maglev system. In this paper, initially non-linear maglev model is linearized, then for the linearized system, transfer function is obtained. The proposed control scheme is basically designed on the basis of number of series coefficient of plant and controller that are taken as $\boldsymbol{m}$ and $\boldsymbol{n}$ respectively. The proposed digital controller is tested for two sampling times ( $\mathrm{Ts}=0.0001$ second $\& 0.001$ second) and different combinations of series coefficients $\boldsymbol{m}$ and $\boldsymbol{n}$ for plant and controller.

The rest of the article is organized as following. The mathematical modeling and control system of magnetic levitation system is given in Section 2. The brief background of series expansion method of controller design algorithm is given in Section 3 and the designing steps of controller for magnetic levitation system are given in Section 4. The simulation and experimental results are obtained in Section 5. The conclusion of the work is given in Section 6 and then after references.

\section{Mathematical Modeling of Magnetic Levitation System}

The systematic diagram of magnetic levitation system is shown in Figure 1 and its electrical equivalent circuit in Figure 2. This experimental setup is made by feedback instrument Ltd. [45].

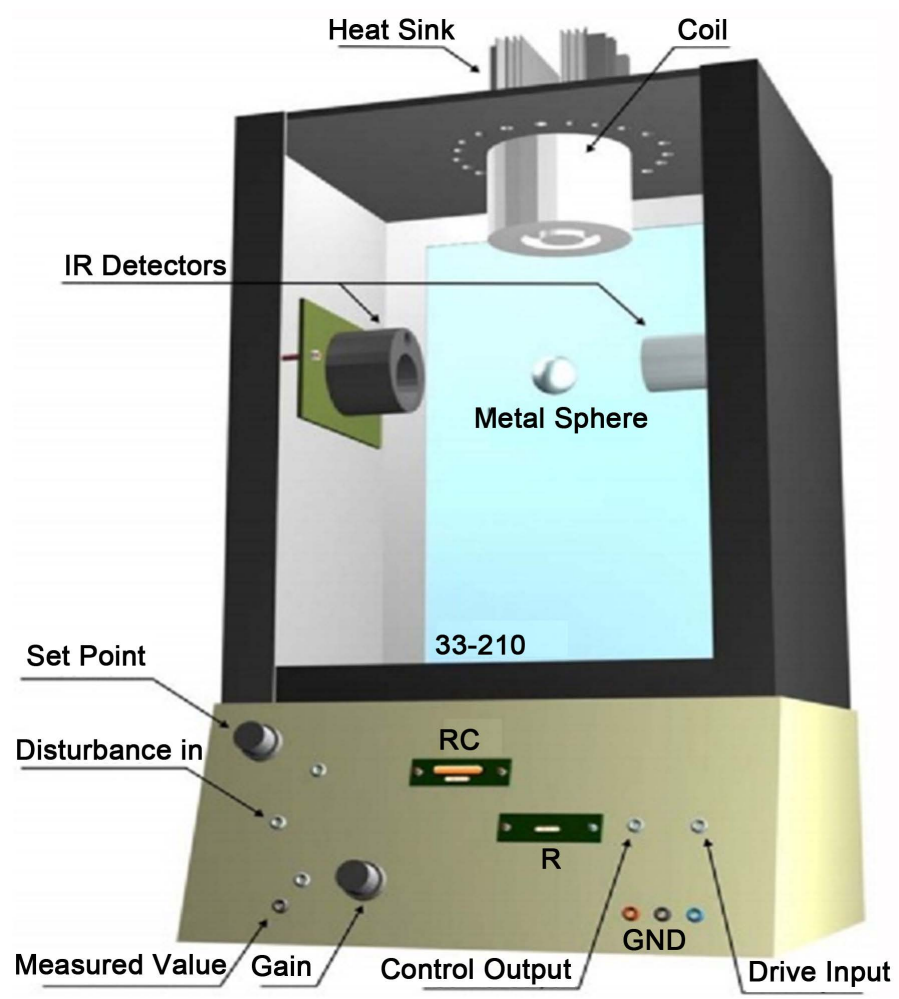

Figure 1. Magnetic levitation system. 


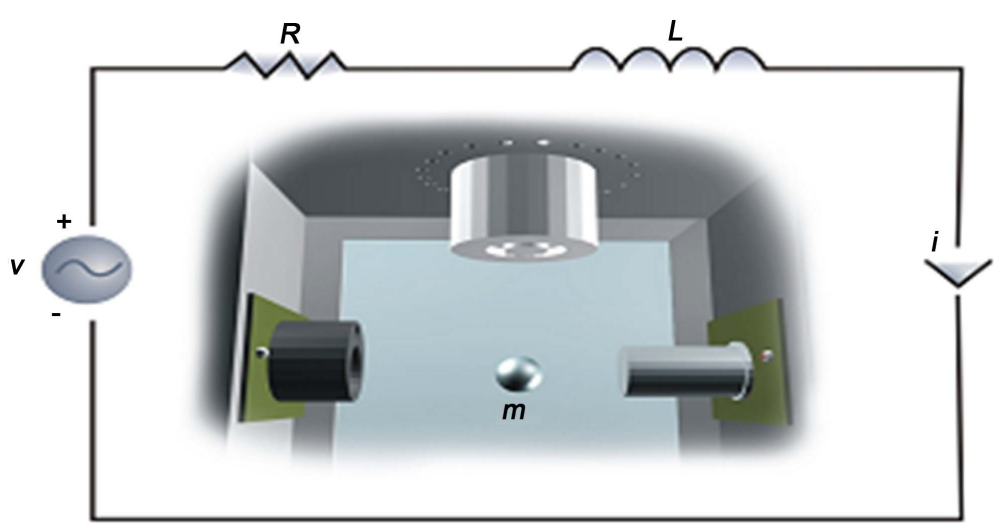

Figure 2. Electrical circuit of magnetic levitation system.

The maglev system mainly consists of four major parts: suspended steel ball, position Infra Red (IR) sensors, controller and actuator (including electro magnet and power amplifier). The steel ball is mainly controlled through current $i$, as clearly indicated in Figure 2. The magnetic force acting on the steel ball depends on two parameters, first, the current $i$, flowing in the coil and the second one is the distance $h$ between coil and the steel ball.

The non-linear model of magnetic levitation system [30] [45], which relates to the current flowing in the coil $i$ and the position $h$ of the steel ball is expressed as:

$$
m \ddot{h}=m g-C \frac{i^{2}}{h^{2}}
$$

where $C$ is a constant value which depends on the parameters of coil, $m$ is mass of the steel ball, $g$ is acceleration due to gravity.

The magnetic levitation system expressed by (1) is nonlinear in nature. For easy analysis and design of controller, the system is linearized about the equilibrium point $\left(i_{0}=0.8 \mathrm{~A}\right.$ and $\left.h_{0}=0.009 \mathrm{~m}\right)$.

$$
f(i, h)=C i^{2} / h^{2}
$$

The linearized model of magnetic levitation system is obtained as:

$$
\Delta \ddot{h}=\left(\left.\frac{\partial f(i, h)}{\partial i}\right|_{i_{0}, h_{0}} \Delta i+\left.\frac{\partial f(i, h)}{\partial i}\right|_{i_{0}, h_{0}} \Delta h\right)
$$

By calculating the partial derivative and taking Laplace transform on both side of Equation (3) we get the transfer function as

$$
\frac{\Delta h}{\Delta i}=\frac{-C_{i}}{s^{2}-C_{h}}
$$

where $C_{i}$ and $C_{h}$ are the constant values for the maglev system and expressed as:

$$
C_{i}=\frac{2 g}{i_{0}}, C_{h}=\frac{2 g}{h_{0}}
$$

In electrical equivalent circuit of magnetic levitation system in Figure 2, the current $i$ 
flowing in the coil is proportional to the control voltage $v$ and expressed as:

$$
i=C_{1} v
$$

where $C_{1}$ is the proportionality constant.

Now, the transfer function can be written as:

$$
\frac{\Delta h}{\Delta v}=\frac{-C_{1} C_{i}}{s^{2}-C_{h}}
$$

where $\Delta v$ is small incremental control voltage around its mean value. By considering $\mathrm{C}_{2}$ which is the gain of (IR) sensor for conversion of position of ball in meter to voltage.

The transfer function of magnetic levitation system with sensor system is obtained as:

$$
\frac{\Delta h_{v}}{\Delta v}=\frac{-C_{1} C_{2} C_{i}}{s^{2}-C_{h}}
$$

where $\Delta h_{v}$ is the (IR) sensor output voltage.

Using given values in the Table 1, the transfer function of the magnetic levitation system is obtained as:

$$
P(s)=\frac{-3518.85}{s^{2}-2180}
$$

The Maglev system (9) has two poles at \pm 46.69 . It is seen that one pole lies in right half of complex s-plane so system is unstable. Hence, the aim is to design a controller, which leads to overall stable system.

\section{Proposed Controller Algorithm}

Let the pulse transfer function of the plant (Maglev System) and controller be $P(z)$ and $C(z)$ respectively [42] [43]. A unity feedback system having a digital controller is shown in Figure 3. The pulse transfer function $P(z)$ and $C(z)$ can be expanded in negative power of $z$ as follows:

Table 1. The parameters of physical Maglev system [30] [45].

\begin{tabular}{cc}
\hline Description of Parameters & Value with Unit \\
\hline mass of the steel ball $(m)$ & $0.02 \mathrm{~kg}$ \\
Acceleration due to gravity $(g)$ & $9.81 \mathrm{~m} / \mathrm{s}^{2}$ \\
Equilibrium value of current $\left(i_{0}\right)$ & $0.8 \mathrm{~A}$ \\
Equilibrium value of position $\left(h_{0}\right)$ & $0.009 \mathrm{~m}$ \\
Control voltage to coil current gain $\left(C_{1}\right)$ & $1.05 \mathrm{~A} / \mathrm{V}$ \\
IR sensor gain $\left(C_{2}\right)$, offset & $143.48 \mathrm{~V} / \mathrm{m},-2.8 \mathrm{~V}$ \\
Control input voltage level $(v)$ & $\pm 5 \mathrm{~V}$ \\
Sensor output voltage level $\left(h_{v}\right)$ & +1.25 to $-3.75 \mathrm{~V}$
\end{tabular}




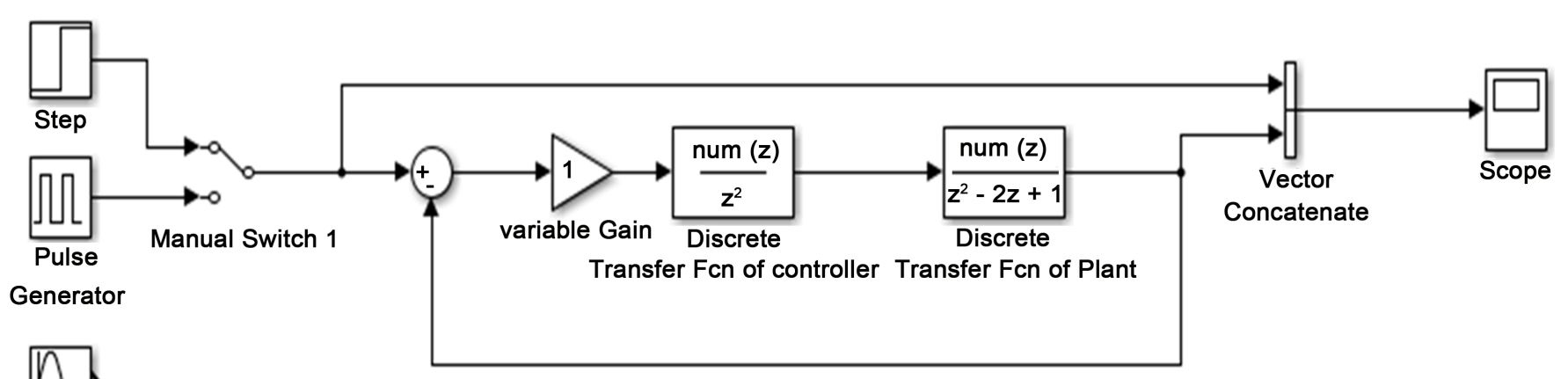

Sine Wave

Figure 3. Proposed simulation diagram.

$$
\begin{aligned}
& P(z)=\sum_{k=0}^{\infty} p_{k} z^{-k} \\
& C(z)=\sum_{k=0}^{\infty} c_{k} z^{-k}
\end{aligned}
$$

The open loop pulse transfer function $O(z)$ can be written as:

$$
O(z)=P(z) C(z)=\sum_{k=0}^{\infty} o_{k} z^{-k}
$$

From (10), (11) and (12) the coefficient $O_{k}$ can be calculated in term of coefficients $p_{j}$ and $c_{k}$ as follows:

$$
\begin{aligned}
& O_{k}=\sum_{j=1}^{k} c_{k-j} p_{j} \quad k=1,2,3, \cdots \\
& O_{0}=0
\end{aligned}
$$

The closed loop pulse transfer function for the above system can be expanded as:

$$
W(z)=\frac{O(z)}{1+O(z)}=\sum_{k=0}^{\infty} w_{k} z^{-k}
$$

Employing (13), the coefficients $w_{k}$ are calculated using the iteration formula:

$$
\begin{aligned}
& w_{0}=0, k=0 \\
& w_{1}=o_{1}, k=1 \\
& w_{k}=o_{k}-\sum_{j=1}^{k-1} o_{j} w_{k-j}, k=2,3, \cdots
\end{aligned}
$$

Thus, the series expansion coefficient of closed loop pulse transfer function is expressed in terms of series expansion coefficient of open loop pulse transfer function and these series coefficients are arbitraterely chosen for obtaining the desired performance. The proposed control scheme is basically design on the basis of number of series coefficient of plant (10) and number of series coefficient of controller (11) on their expansion that are taken as $\boldsymbol{m}$ and $\boldsymbol{n}$ respectively during the design procedure that are discussed in next section. 


\section{Controller Designing Steps}

Let the pulse sequence $\left\{w_{k} ; k=0,1,2,3, \cdots, m\right\}$ represents desired unit pulse response. Now, we have to design a controller so that the sequence of closed loop system is approximately matched with the desired one. For designing of the controller, we have to follow the steps given:

Step 1: First specify the desired pulse response sequence $\left\{w_{k} ; k=0,1,2,3, \cdots, m\right\}$ and the number of series coefficient of the plant $\boldsymbol{m}$ and controller coefficients $\boldsymbol{n}$ $(\boldsymbol{n}<\boldsymbol{m}-1)$ to be designed.

Step 2: Using the (15) solve for $O_{k} \quad(k=2,3,4, \cdots, m)$ with iteration formula:

$$
\begin{aligned}
& O_{1}=w_{1} \\
& O_{k}=w_{k}+\sum_{j=1}^{k-1} o_{j} w_{k-j} \quad k=2,3, \cdots, m
\end{aligned}
$$

Step 3: Now substitute $O_{k}(k=1,2, \cdots, m)$ into (13) and construct an equation for $c_{k}$

$$
P(z) * C(z)=O(z)
$$

where

$$
P=\left[\begin{array}{ccccccccc}
p_{1} & 0 & 0 & 0 & \cdot & \cdot & \cdot & 0 & 0 \\
p_{2} & p_{1} & 0 & 0 & \cdot & \cdot & \cdot & 0 & 0 \\
\cdot & \cdot & & & & & & \cdot & \cdot \\
\cdot & \cdot & & & & & \cdot & \cdot \\
\cdot & \cdot & & & & & \cdot & \cdot \\
p_{n-1} & p_{n} & \cdot & \cdot & \cdot & \cdot & \cdot & p_{2} & p_{1} \\
\cdot & \cdot & & & & & \cdot & \cdot \\
\cdot & \cdot & & & & & \cdot & \cdot \\
\cdot & \cdot & & & & & \cdot & \cdot \\
p_{m} & p_{m-1} & \cdot & \cdot & \cdot & \cdot & \cdot & p_{m-n+1} & p_{m-n}
\end{array}\right]
$$

Step 4: Now, solve Equation (17) by the method of least squares and the solution of the calculated controller coefficient $c^{*}$ is obtained as:

$$
c^{*}=\left(P^{\mathrm{T}} * P\right)^{-1} * P^{\mathrm{T}} * O
$$

Step 5: The controller coefficients are expressed as:

$$
C(z)=c_{0}^{*}+c_{1}^{*} z^{-1}+c_{2}^{*} z^{-2}+\cdots+c_{n-1}^{*} z^{-n+1}+c_{n}^{*} z^{-n}
$$

The (22) is the designed controller for a specific value of series coefficients of plant and controller as $\boldsymbol{m}$ and $\boldsymbol{n}$ respectively.

Note 1: If the response of closed loop system obtained from (22) along with (10) does not track the desired trajectory, then value of series coefficients of pant $\boldsymbol{m}$ and controller $\boldsymbol{n}$ are increased and all the above five steps are repeated. 
The next section presents the simulation at different sampling times and various inputs as well as the hardware results for sinusoidal input when controller given by (22) is applied on maglev system (9).

\section{Simulation and Hardware Experimental Results}

The simulation diagram of proposed digital control algorithm for the controlling of maglev system is given in Figure 3.

The simulations are carried out for two cases, one at sampling time Ts $=0.0001$ second and secondly at 0.001 second.

Case 1: Plots at sampling time $(\mathrm{Ts})=\mathbf{0 . 0 0 0 1}$ second

Let the sampling time (Ts) is 0.0001 second and the desired pulse sequence is $W=[0$ $\begin{array}{llllllllllllll}0.1 & 0.2 & 0.3 & 0.4 & 0.5 & 0.6 & 0.7 & 0.8 & 0.9 & 1 & 1 & 1 & 1 & 1\end{array} \cdots$. Now for step input we have to design a controller so that it can track the step input. Once the controller is designed with the help of series expansion of pulse transfer function subjected to step input then it is also effective for all type of inputs. The performance of designed controller depends upon number of series coefficients $\boldsymbol{m}$ and $\boldsymbol{n}$ considered for plant and controller respectively and plots are given for following conditions that are given below.

\section{Simulation results for various inputs at sampling time $\mathrm{Ts}=0.0001$ second}

The simulation results for various combination of number of considered series coefficient of plant and controller are discussed below

\section{1) For $m=25 \& n=2$}

In this case the controller series coefficient is obtained as $C=\left[\begin{array}{lll}-917.2 & -2015 & 2899.4\end{array}\right]$. After applying this controller on the magnetic levitation system (9), the closed loop discrete transfer function is obtained as:

$$
\frac{0.01614 z^{3}+0.05159 z^{2}-0.01556 z-0.05101}{z^{4}-1.984 z^{3}+1.052 z^{2}-0.01556 z-0.05101}
$$

The eigen values of (23) lie at $0.9911,0.8391,0.3362$ and -0.1825 and all are within the unit circle. Hence, system is stable. The simulation results are plotted for different inputs such as step, square wave and sinusoidal in Figures 4(a)-(c).

2) For $m=25 \& n=3$

In this case, the proposed controller coefficient is obtained as

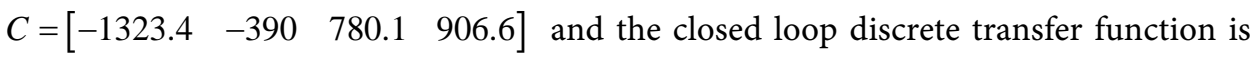
written as:

$$
\frac{0.02328 z^{4}+0.03015 z^{3}-0.006864 z^{2}-0.02968 z-0.01595}{z^{5}-1.977 z^{4}+1.03 z^{3}-0.006864 z^{2}-0.02968 z-0.01595}
$$

It is found that, all the eigen values of (24) lie within the unit circle. The simulation results are plotted for different inputs such as step, square wave and sinusoidal from Figures 5(a)-(c).

The step performance of proposed controller is summarized in Table 2.

Remark 1: Looking at the Table 2 for cases $m=25 \& n=2$ and $m=25 \& n=3$, it is seen that on increasing the number of controller coefficients $\boldsymbol{n}$ from 2 to 3 , settling time 


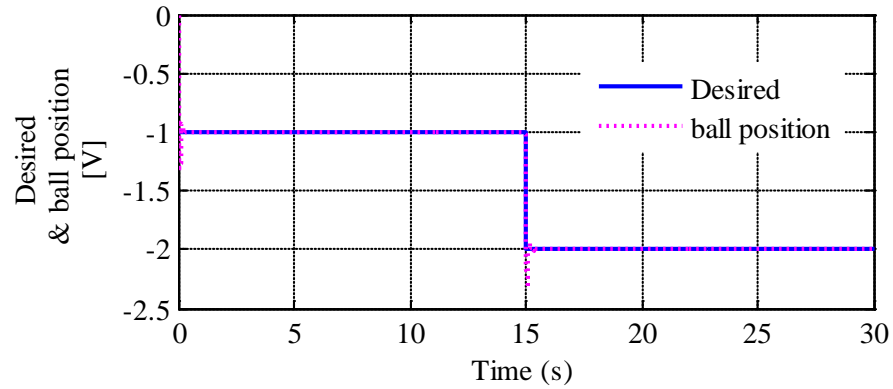

(a)

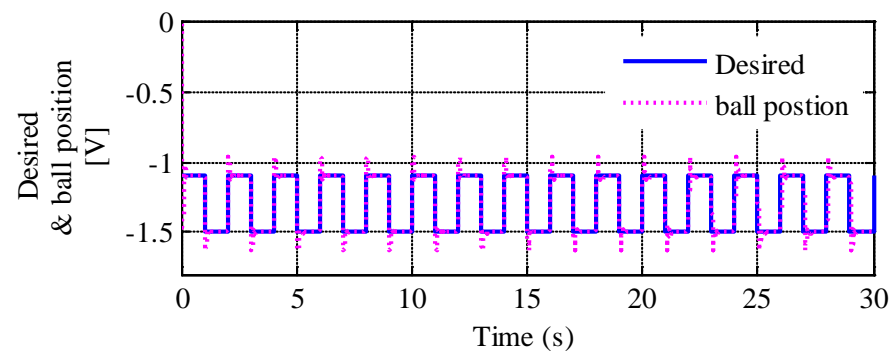

(b)

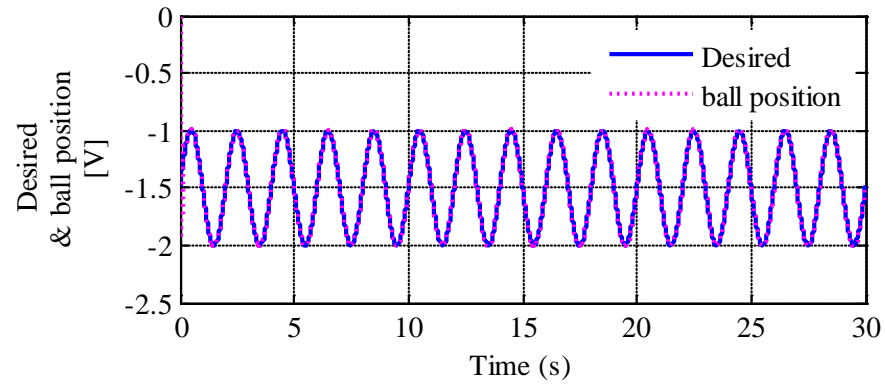

(c)

Figure 4. (a) Response for step input; (b) Response for square wave input; (c) Response for sinusoidal.

Table 2. Performance of proposed controller for step input (Ts $=0.0001$ second).

\begin{tabular}{cccccc}
\hline $\boldsymbol{m} \& \boldsymbol{n}$ & $\begin{array}{c}\text { Rise Time } \\
\text { (second) }\end{array}$ & $\begin{array}{c}\text { Settling Time } \\
\text { (second) }\end{array}$ & Overshoot & Peak & $\begin{array}{c}\text { Peak Time } \\
\text { (second) }\end{array}$ \\
\hline $\boldsymbol{m}=\mathbf{2 5} \& \boldsymbol{n}=\mathbf{2}$ & 0.001 & 0.0111 & $3.65 \%$ & 1.05 & 0.0038 \\
$\boldsymbol{m}=\mathbf{2 5} \& \boldsymbol{n}=\mathbf{3}$ & 0.001 & 0.0057 & $2.19 \%$ & 1.04 & 0.0039 \\
\hline
\end{tabular}

is reduced from 0.0111 second to 0.0057 second and overshoot is also decreased from $3.65 \%$ to $2.19 \%$. The simulation results for various input clearly state that the proposed algorithms is gives the better tracking response whatever the input such as step, square and sinusoidal.

Note 2: Experimental results cannot be verified for sampling time Ts $=0.0001$ second because the magnetic levitation provided by Feedback Instrument is manufactured for sampling time Ts $=0.001$ second. 


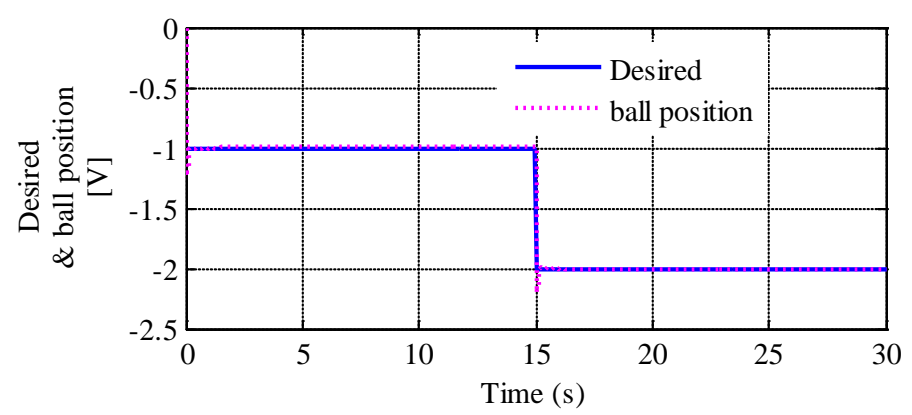

(a)

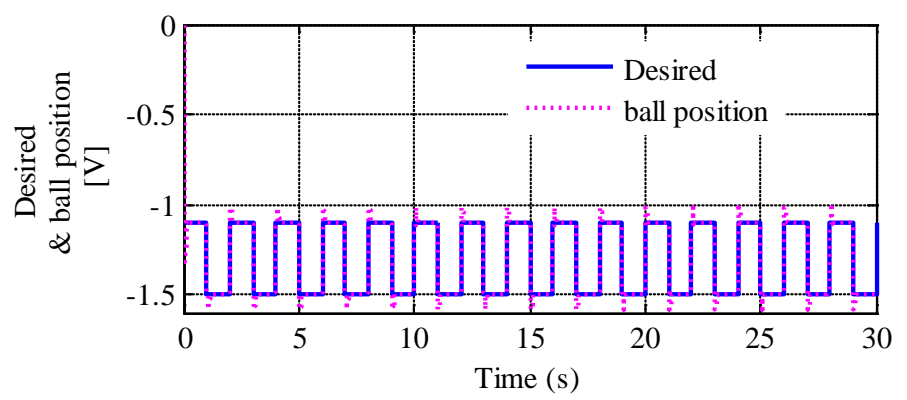

(b)

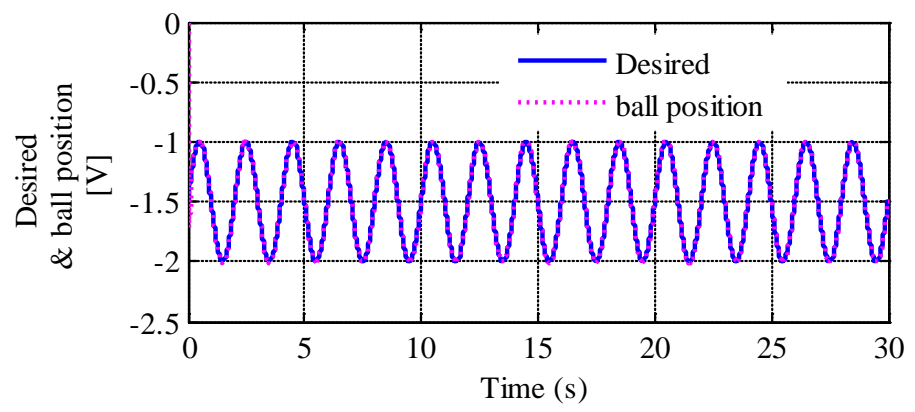

(c)

Figure 5. (a) Response for step input; (b) Response for square wave input; (c) Response for sinusoidal input.

Now, the performance of designed controller is tested at sampling time 0.001 second through simulation as well as on the system hardware (Magnetic Levitation System 33 210, Feedback Instruments) which is presented through Case 2.

\section{Case 2: Plots at sampling time (Ts) $=0.001$ second}

The similar steps are carried out as in Case $\mathbf{1}$ for designing of controller. The simulation and hardware experimental results are plotted for following conditions as in Section A and Section B respectively in below.

\section{A. Simulation results for various inputs at sampling time $\mathrm{T} s=0.001$ second \\ 1) For $m=7 \& n=2$}

In this case the controller coefficient is obtained as $C=\left[\begin{array}{lll}-13.5754 & -2.4951 & 14.1198\end{array}\right]$ and with this controller the closed loop discrete transfer function for system (9) is obtained as: 


$$
\frac{0.02389 z^{3}+0.02828 z^{2}-0.02046 z-0.02485}{z^{4}-1.978 z^{3}+1.028 z^{2}-0.02046 z-0.02485}
$$

and all the eigen values of (25) lie within the unit circle. The simulation results are plotted for various inputs as shown in Figures 6(a)-(c).

2) For $m=12 \& n=3$

In this case the controller coefficients are obtained as $C=\left[\begin{array}{llll}-10.8190 & -13.5268 & 27.1775 & -4.5759\end{array}\right]$. The closed loop discrete transfer for system (9) with this controller is obtained as:

$$
\frac{0.01904 z^{4}+0.04284 z^{3}-0.02402 z^{2}-0.03977 z+0.008052}{z^{5}-1.983 z^{4}+1.043 z^{3}-0.02402 z^{2}-0.03977 z+0.008052}
$$

Here, also all the eigen values of (26) lie within unit circle. The results are plotted for various inputs as shown in Figures 7(a)-(c).

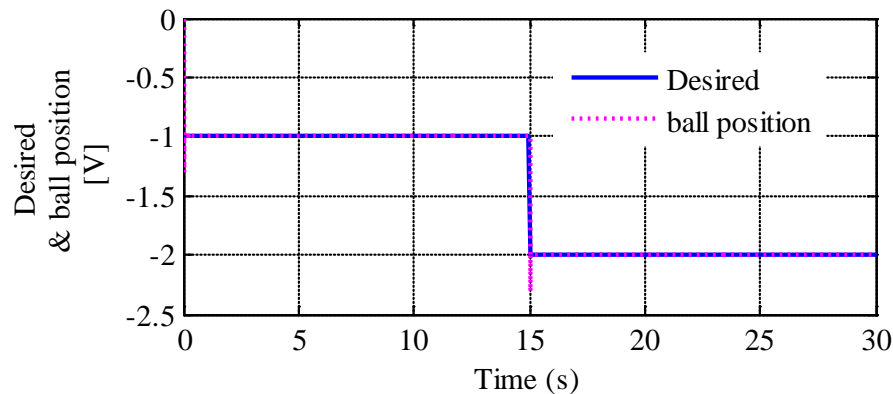

(a)

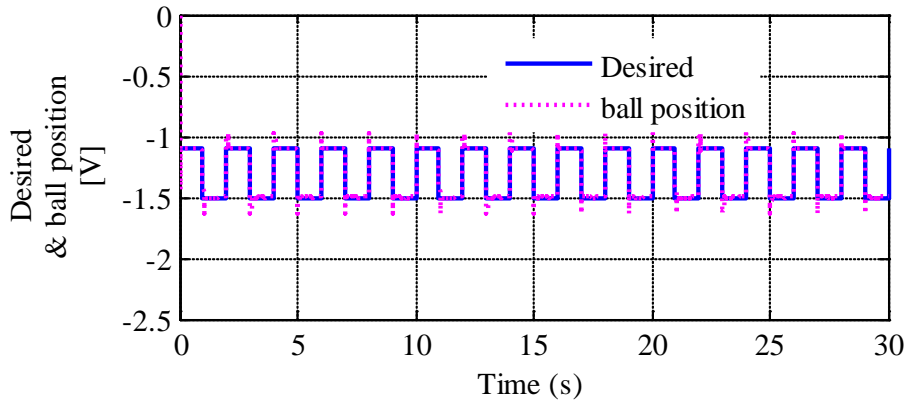

(b)

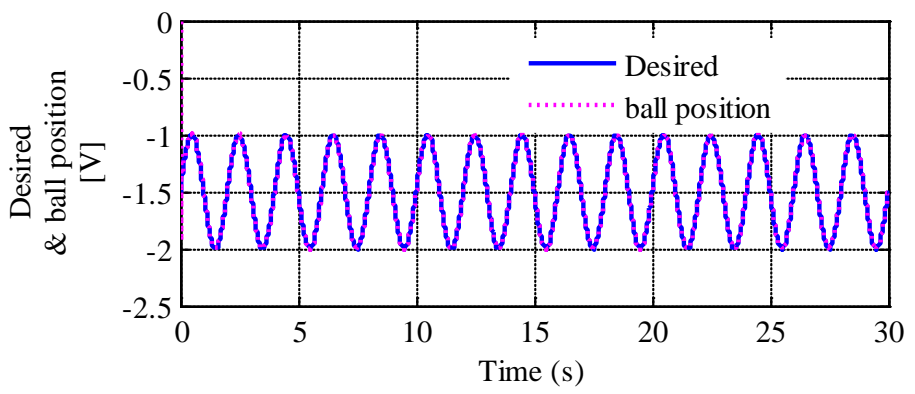

(c)

Figure 6. (a) Response for step input; (b) Response for square wave input; (c) Response for sinusoidal input. 


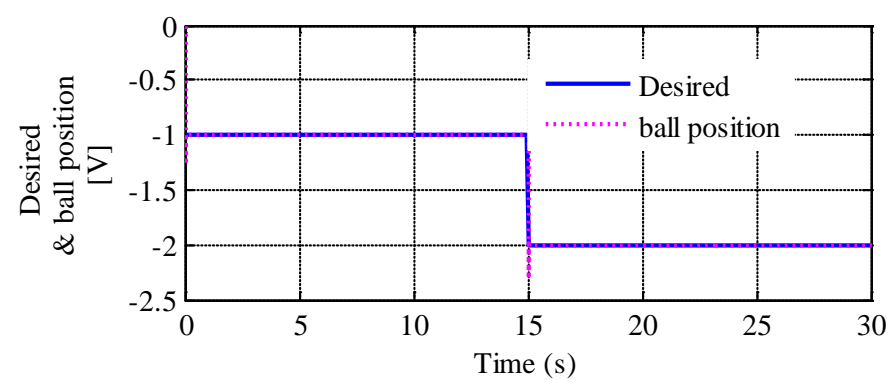

(a)

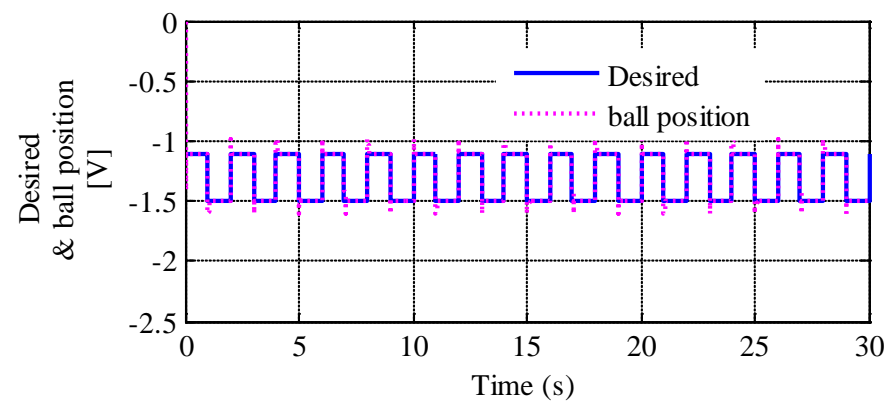

(b)

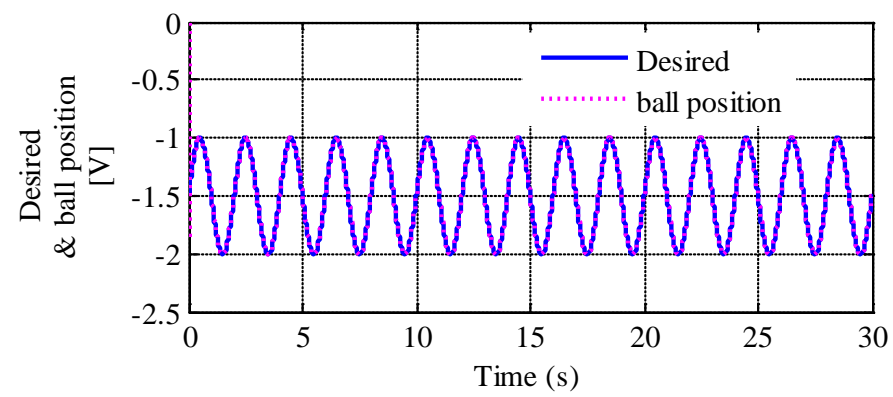

(c)

Figure 7. (a) Response for step input; (b) Response for square wave input; (c) Response for sinusoidal input.

Remark 2: The simulation results for Case 2 of $m=7 \& n=2$ and $m=12 \& n=3$ are plotted in Figures 6(a)-(c) and Figures 7(a)-(c), from the above Figures it is clear that, tracking is almost achieved for desired trajectories such as step, square and sinusoidal. The step performances for this case are summarized in Table 3.

It is seen from Table 3, the transient response (peak overshoot and settling time) has improved remarkably as the order of plant and controller coefficients are increased from $m=7 \& n=2$ to $m=12 \& n=3$. The experimental result has been carried in Section B.

\section{B. Hardware experimental results}

The effectiveness of proposed controller is verified on setup of maglev system (33-942S) provided by feedback instrument. The maglev setup has two PCI port as PCI1711 Lab I/O ADC port is configured for plant output and PCI1711 Lab I/O DAC port is dedicated for input to the maglev system. The maglev system is manufactured 
Table 3. Performance of proposed controller for step input (Ts $=0.001$ second).

\begin{tabular}{cccccc}
\hline $\boldsymbol{m} \& \boldsymbol{n}$ & $\begin{array}{c}\text { Rise Time } \\
\text { second) }\end{array}$ & $\begin{array}{c}\text { Settling Time } \\
\text { (second) }\end{array}$ & Overshoot & Peak & $\begin{array}{c}\text { Peak Time } \\
\text { (second) }\end{array}$ \\
\hline $\boldsymbol{m}=\mathbf{7} \& \boldsymbol{n}=\mathbf{2}$ & 0.01 & 0.07 & 13.43 & 1.66 & 0.04 \\
$\boldsymbol{m}=\mathbf{1 2} \& \boldsymbol{n}=\mathbf{3}$ & 0.01 & 0.07 & 7.39 & 1.66 & 0.04 \\
\hline
\end{tabular}

for sampling time Ts $=0.001$ second. The proposed hardware experimental diagram is given in Figure 8.

The hardware results are tested for all two cases as discussed in Section A for Case 2 and hardware result is plotted for sinusoidal input at sampling tine 0.001 second. The position of ball to reference input is presented in voltage [V] as well as in meter $(\mathrm{m})$ along with control effort in voltage [V].

\section{1) For $m=7 \& n=2$}

For this case, hardware experimental result is shown from Figure 9 for sinusoidal input.

2) For $m=12 \& n=3$

For this case, the hardware experimental result is shown from Figure 10 for sinusoidal input.

Remark 3: From the hardware experimental results as shown in Figure 9(a) and Figure 9(b) and Figure 10(a) and Figure 10(b), it is noticed that the peak overshoot is less in case of $\boldsymbol{m}=12 \& \boldsymbol{n}=\mathbf{3}$ as compared to the when $\boldsymbol{m}=7 \& \boldsymbol{n}=\mathbf{2}$.

It could be remarked here that on increasing the series coefficients of plant and controller, the transient and steady state behavior of system have been improved.

\section{Comparison}

The designed control strategy is quite useful for complex system and it can be easily implemented on any real time system via computer-programmed algorithm where as conventional continuous control scheme may suffer during real time implementation of linear or nonlinear control algorithms. To show the effectiveness of proposed control strategy, a comparative simulation result of designed control scheme ( $m=25 \& \boldsymbol{n}=\mathbf{3}$ at sampling time 0.0001 second) with conventional PID $\left(k_{C}=-4, \tau_{I}=0.5, \tau_{D}=0.05\right)$ and FOPID ( $\left.k_{p}=-19, k_{i}=-18.5, k_{d}=-0.18, \lambda=0.5, \mu=0.85\right)$ control scheme for the considered maglev system (9) are shown in Figure 11.

The comparative results analysis with conventional PID and FOPID controller are given in Table 4.

From the Figure 11, it is clear that the designed controller is performed well and ball of maglev system tracks more accurately to the reference trajectory. The system performances are improved, which are clearly listed in Table 4 . The performance designed controller is also depend on sampling time of specified system that are also noticed via the Table 2 and Table 3 where system performances are subsequently improved by increasing the sapling time and series coefficients of plant and controller. Due to hardware limitation, the experimental results are carried out for sampling time Ts $=0.001$ second only and cannot be verified for sampling time Ts $=0.0001$ second because the 


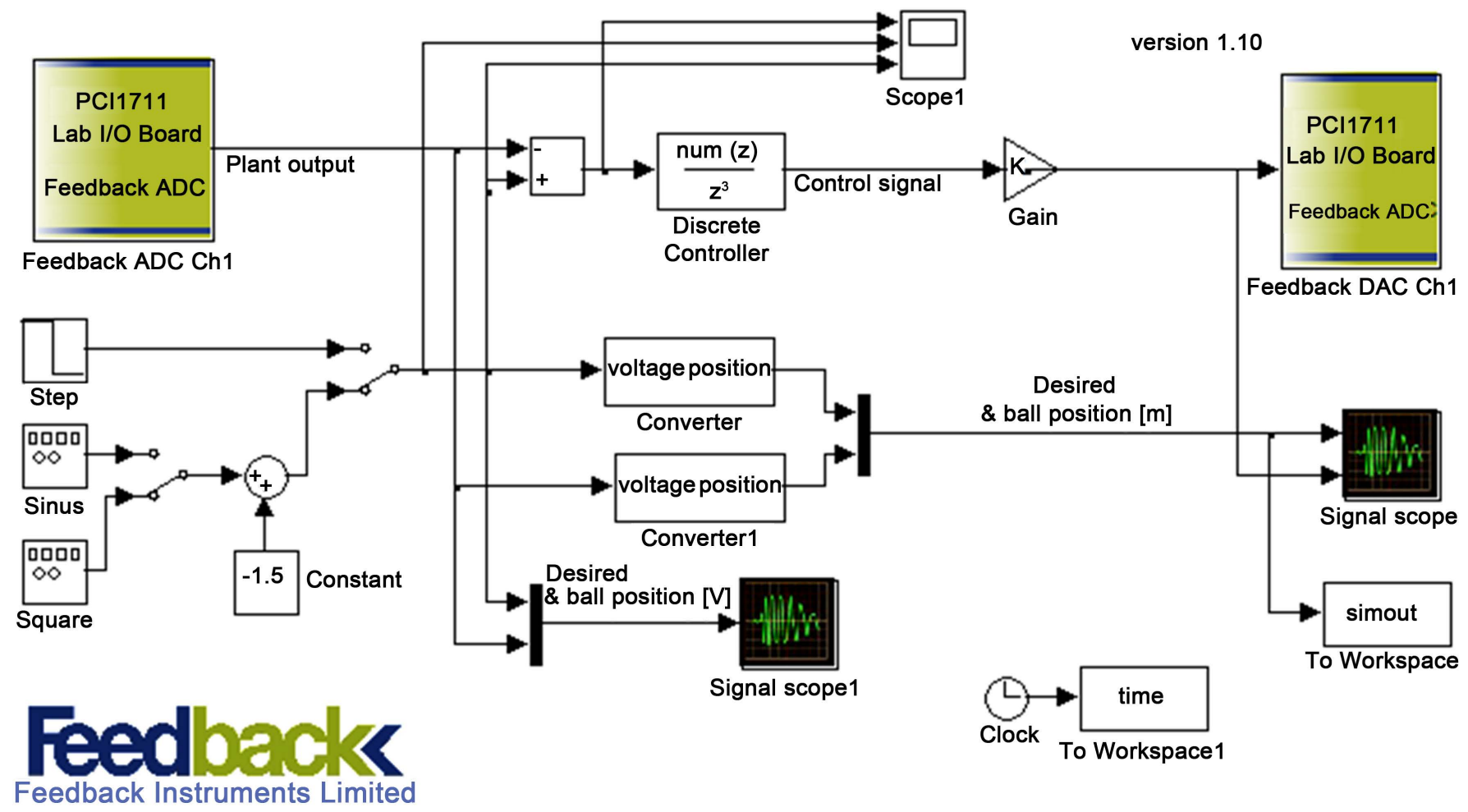

Figure 8. Hardware experimental diagram.

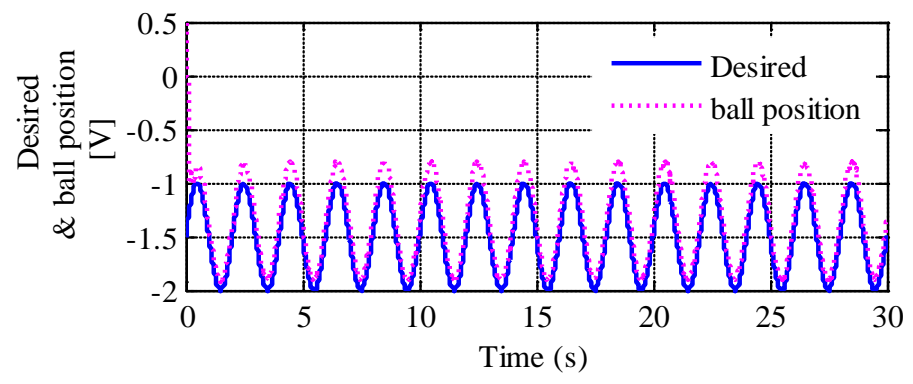

(a)
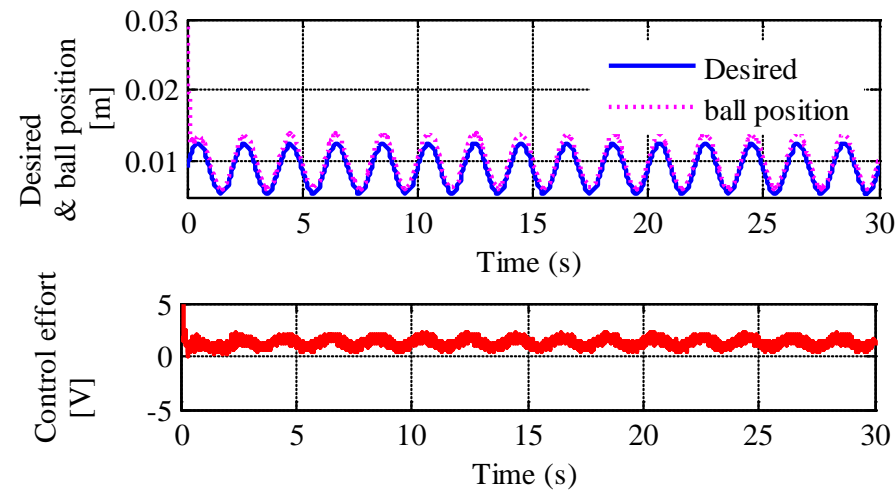

(b)

Figure 9. (a) Response for sinusoidal input (hardware); (b) Desired \& ball position (m) and Control effort $[\mathrm{V}]$ for sinusoidal input (hardware). 


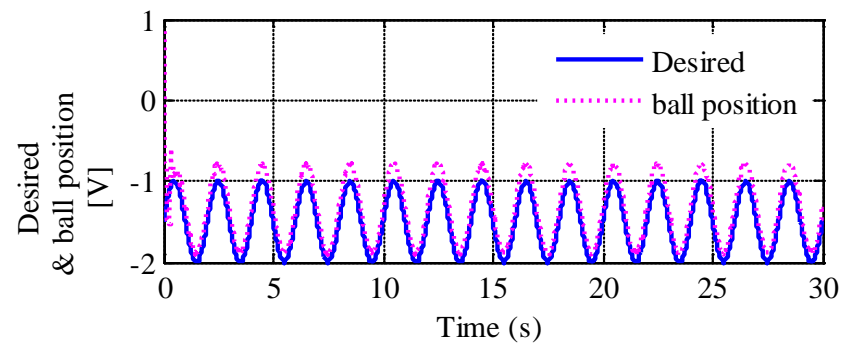

(a)
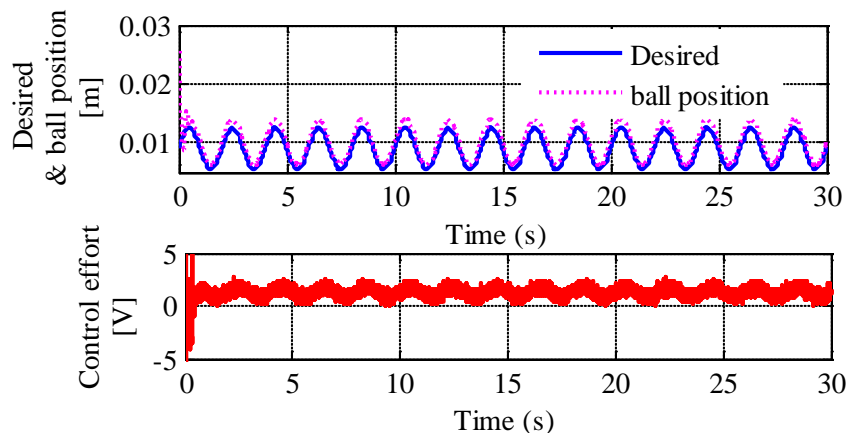

(b)

Figure 10. (a) Response for sinusoidal input (hardware); (b) Desired \& ball position (m) and Control effort $[\mathrm{V}]$ for sinusoidal input (hardware).

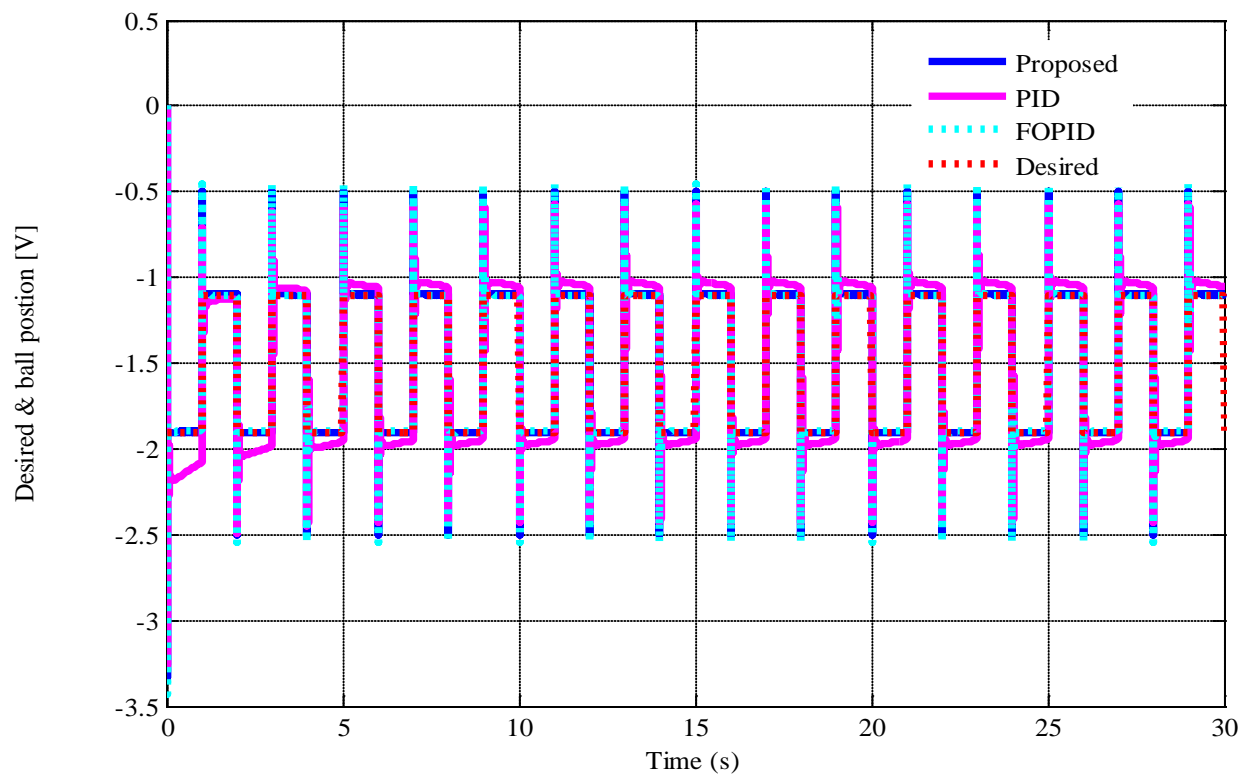

Figure 11. Desired and ball position (comparative).

magnetic levitation provided by Feedback Instrument is manufactured for sampling time $\mathrm{Ts}=0.001$ second .

The designed controller lies in $\mathrm{z}$-domain and it will bypass the requirement of higher sampling rate. Another beauty of this design algorithm is that it is applicable to any higher order system also. 
Table 4. Comparative result of proposed control, PID and FOPID control strategy.

\begin{tabular}{|c|c|c|c|c|c|}
\hline Type of Control & $\begin{array}{l}\text { Rise Time } \\
\text { (second) }\end{array}$ & $\begin{array}{l}\text { Settling Time } \\
\text { (second) }\end{array}$ & Overshoot & Peak & $\begin{array}{l}\text { Peak Time } \\
\text { (second) }\end{array}$ \\
\hline $\begin{array}{l}\text { Proposed control scheme } \\
\quad m=25 \& n=3\end{array}$ & 0.001 & 0.0057 & $2.19 \%$ & 1.040 & 0.0039 \\
\hline $\begin{array}{l}\text { With Conventional PID control [45] } \\
\qquad k_{C}=-4, \tau_{I}=0.5, \tau_{D}=0.05\end{array}$ & 0.0030 & 0.9211 & $15.07 \%$ & 1.1507 & 0.1327 \\
\hline $\begin{array}{l}\text { With FOPID Control [45] } \\
k_{p}=-19, k_{i}=-18.5 \\
k_{d}=-0.18, \lambda=0.5, \mu=0.85\end{array}$ & 0.0034 & 0.9712 & 37.6215 & 1.3767 & 0.0086 \\
\hline
\end{tabular}

\section{Conclusion}

An algorithm for digital controller design has been proposed and implemented for a magnetic levitation system. The proposed digital controller is designed based on series expansion of pulse transfer function by solving a linear equation using the method of least squares. The simulation and hardware experimental results are given to show the applicability of proposed controller. The designed controller provides better tracking and transient response (settling time and peak overshoots etc.) as number of series coefficient of plant and controller is increased. The designed algorithm used for the control input is not iterative so the calculation is very fast. The proposed control technique is also compared with convention PID and FOPID control scheme. In this method the reliability criterion for a controller should be satisfied when the desired pulse response sequence is known. This method can be used for stable plant as well as unstable plant. Furthermore, it is possible to extend the method for multi input multi output (MIMO) system also.

\section{References}

[1] Rogg, D. (1984) General Survey of the Possible Applications and Development Tendencies of Magnetic Levitation Technology. IEEE Transactions on Magnetics, 20, 1696-1701. http://dx.doi.org/10.1109/TMAG.1984.1063347

[2] Yaghoubi, H. (2013) The Most Important Maglev Applications. Journal of Engineering, 2013, 1-19. http://dx.doi.org/10.1155/2013/537986

[3] Yamamura, S. (1976) Magnetic Levitation Technology of Tracked Vehicles Present Status and Prospects. IEEE Transactions on Magnetics, 12, 874-878.

http://dx.doi.org/10.1109/TMAG.1976.1059125

[4] Sinha, P. (1984) Design of a Magnetically Levitated Vehicle. IEEE Transactions on Magnetics, 20, 1672-1674. http://dx.doi.org/10.1109/TMAG.1984.1063552

[5] Eastham, A.R. and Hayes, W.F. (1988) Maglev Systems Development Status. IEEE Aerospace and Electronic Systems Magazine, 3, 21-30. http://dx.doi.org/10.1109/62.843

[6] Lee, W.H., Kim, K.C. and Lee, J. (2006) Review of Maglev Train Technologies. IEEE Transactions on Magnetics, 42, 1917-1925. http://dx.doi.org/10.1109/TMAG.2006.875842

[7] Mirica, K.A., Phillips, S.T., Mac, E.C.R. and Whitesides, G.M. (2010) Magnetic Levitation in 
the Analysis of Foods and Water. Journal of Agricultural and Food Chemistry, 58, 65656569. http://dx.doi.org/10.1021/jf100377n

[8] Wu, H., Wang, Z. and Lv, X. (2011) Design and Simulation of Axial Flow Maglev Blood Pump. International Journal of Information Engineering and Electronic Business, 3, 42-48. http://dx.doi.org/10.5815/ijieeb.2011.02.06

[9] Qian, K.X., Zeng, P., Ru, W.M. and Yuan, H.Y. (2006) New Concepts and New Design of Permanent Maglev Rotary Artificial Heart Blood Pumps. Medical Engineering \& Physics, 28, 383-388. http://dx.doi.org/10.1016/j.medengphy.2005.07.007

[10] Qian, K.X. and Jing, T. (2008) Use of PM Bearings in Permanent Maglev Centrifugal Pumps for Stability Investigation. Proceedings of the $1^{\text {st }}$ International Conference on Biomedical Engineering and Informatics (BMEI08), Sanya, 27-30 May 2008, 535-538. http://dx.doi.org/10.1109/bmei.2008.70

[11] Sivrioglu, S. and Nonami, K. (1998) Sliding Mode Control with Time-Varying Hyper- Plane for AMB System. IEEE/ASME Transactions on Mechatronics, 3, 51-59. http://dx.doi.org/10.1109/3516.662868

[12] Losch, F., Gahler, C. and Herzog, R. (1999) Low Order $\mu$-Synthesis Controller Design for a Large Boiler Feed Pump Equipped with Active Magnetic Bearing. Proceedings of the 1999 IEEE International Conference on Control Applications, Kohala, 22-27 August 1999, 564569. http://dx.doi.org/10.1109/CCA.1999.806707

[13] Mukhopadhyay, S.C., Ohji, T., Iwahara, M. and Yamada, S. (2000) Modeling and Control of a New Horizontal-Shaft Hybrid-Type Magnetic Bearing. IEEE Transactions on Industrial Electronics, 47, 100-108. http://dx.doi.org/10.1109/41.824131

[14] Komori, M., Kumamoto, M. and Kobayashi, H. (1998) A Hybrid-Type Superconducting Magnetic Bearing System with Nonlinear Control. IEEE Transactions on Applied Superconductivity, 8, 79-83. http://dx.doi.org/10.1109/77.678445

[15] Maslen, E.H., Bearnson, G.B., Allaire, P.E., Flack, R.D., Baloh, M., Hilton, E., Noh, M.D., Olsen, D.B., Khanwilkar, P.S. and Long, J.D. (1998) Feedback Control Applications in Artificial Hearts. IEEE Control Systems Magazine, 18, 26-34. http://dx.doi.org/10.1109/37.736009

[16] Lee, J.H., Allaire, P.E., Tao, G., Decker, J. and Zhang, X. (2003) Experimental Study of Sliding Mode Control for a Benchmark Magnetic Bearing System and Artificial Heart Pump Suspension. IEEE Transactions on Control Systems Technology, 11, 128-138. http://dx.doi.org/10.1109/TCST.2002.806457

[17] Shen, J.X., Tseng, K.J., Vilathgamuwa, D.M. and Chan, W.K. (2000) A Novel Compact PMSM with Magnetic Bearing for Artificial Heart Application. IEEE Transactions on Industry Applications, 36, 1061-1068. http://dx.doi.org/10.1109/28.855961

[18] Tsiotras, P. and Wilson, B.C. (2003) Zero and Low-Bias Control Designs for Active Magnetic Bearings. IEEE Transactions on Control Systems Technology, 11, 889-904. http://dx.doi.org/10.1109/TCST.2003.819593

[19] Xianwei, F. and Jinggang, Z. (2012) A Survey of Control Strategy for Magnetic Suspension Ball System. Proceeding of 31st Chinese Control Conference, Taiyuan, 25-27 July 2012, 665-670.

[20] Reddy, R.L.K. and Marutheeswar, G.V. (2013) Different Controlling Methods and PID Controller Design For Magnetic Levitation System. International Journal of Advanced Research in Electrical, Electronics and Instrumentation Engineering, 2, 6210-6217.

[21] Barie, W. and Chiasson, J. (1996) Linear and Nonlinear State-Space Controller for Magnetic Levitation. International Journal of Systems Science, 27, 1153-1163. 
http://dx.doi.org/10.1080/00207729608929322

[22] Song, R. and Chen, Z. (2014) Design of PID Controller for Maglev System Based on an Improved PSO with Mixed Inertia Weight. Journal of Networks, 9, 1509-1517.

http://dx.doi.org/10.4304/jnw.9.6.1509-1517

[23] Maji, L., Roy, P. and Roy, B.K. (2015) Design of PID and FOPID Controllers Based on Bacterial Foraging and Particle Swarm Optimization for Magnetic Levitation System. Indian Control Conference, Chennai, 5-7 January 2015, 463-468.

[24] Muresan, C.I., Ionescu, C., Folea, S. and Keyser, R.D. (2014) Fractional Order Control of Unstable Processes: The Magnetic Levitation Study Case. Nonlinear Dynamics, 80, 17611772. http://dx.doi.org/10.1007/s11071-014-1335-Z

[25] Kumar, V., Nakara, B.C. and Mittal, A.P. (2011) A Review on Classical and Fuzzy PID Controllers. International Journal of Intelligent Control and Systems, 16, 170-181.

[26] Golob, M. and Tovornik, B. (2003) Modeling and Control of the Magnetic Suspension System. ISA Transactions, 42, 89-100. http://dx.doi.org/10.1016/S0019-0578(07)60116-5

[27] Yadav, S., Tiwari, J.P. and Nagar, S.K. (2012) Digital Control of Magnetic Levitation System Using Fuzzy Logic Controller. International Journal of Computer Applications, 41, 27-31. http://dx.doi.org/10.5120/5826-8141

[28] Sakalli, A., Kumbasar, T., Yesil, E. and Hagras, H. (2014) Analysis of the Performance of Type-1, Self-Tuning Type-1 and Interval Type-2 Fuzzy PID Controller on the Magnetic Levitation System. International Conference on Fuzzy Systems, Beijing, 6-11 July 2014, 18591866.

[29] Chen, C.A., Chiang, H.K. and Shen, J.C. (2009) Fuzzy Sliding Mode Control of Magnetic Ball Suspension System. International Journal of Fuzzy Systems, 11, 97-106.

[30] Ghos, A., Krishnan, T.R., Tejaswy, P., Mandal, A., Pradhan, J.K. and Ranasingh, S. (2014) Design and Implementation of a 2-DOF PID Compensation for Magnetic Levitation Systems. ISA Transactions, 53, 1216-1222. http://dx.doi.org/10.1016/j.isatra.2014.05.015

[31] Chiang, H.K., Chen, C.A. and Li, M.Y. (2006) Integral Variable-Structure Grey Control for Magnetic Levitation System. Proceedings of IEEE Electric Power Applications, 153, 809814. http://dx.doi.org/10.1049/ip-epa:20060056

[32] Yang, Z.J., Kunitoshi, K., Kanae, S. and Wada, K. (2008) Adaptive Robust Output-Feedback Control of a Magnetic Levitation System by K-Filter Approach. IEEE Transactions on Industrial Electronics, 55, 390-399. http://dx.doi.org/10.1109/TIE.2007.896488

[33] Saravanan, T., Saritha, G. and Udayakumar, R. (2013) A Robust H-Infinity Two Degree of Freedom Control for Electro Magnetic Suspension System. Middle East Journal of Scientific Research, 18, 1827-1831.

[34] Shen, J.C. (2008) Ho Control and Sliding Mode Control of Magnetic levitation System. Asian Journal of Control, 4, 333-340. http://dx.doi.org/10.1111/j.1934-6093.2002.tb00361.x

[35] Lin, F.J., Chen, S.Y. and Shyu, K.K. (2009) Robust Dynamic Sliding-Mode Control Using Adaptive RENN for Magnetic Levitation System. IEEE Transactions on Neural Networks, 20, 938-951. http://dx.doi.org/10.1109/TNN.2009.2014228

[36] Cho, D., Kato, Y. and Spilman, D. (1993) Sliding Mode and Classical Controllers in Magnetic Levitation Systems. IEEE Control Systems, 13, 42-48. http://dx.doi.org/10.1109/37.184792

[37] Gutierrez, H.M. and Ro, P.I. (2005) Magnetic Servo Levitation by Sliding-Mode Control of Nonaffine Systems with Algebraic Input Invertibility. IEEE Transactions on Industrial Electronics, 52, 1449-1455. http://dx.doi.org/10.1109/TIE.2005.855651 
[38] Lin, C.M., Lin, M.H. and Chen, C.W. (2011) SoPC-Based Adaptive PID Control System Design for Magnetic Levitation System. IEEE Systems Journal, 5, 278-287.

http://dx.doi.org/10.1109/ISYST.2011.2134530

[39] Jury, E.I. (1958) Sampled-Data Control System. Wiley, New York.

[40] Ogata, K. (1995) Discrete-Time Control Systems. Pearson, New York.

[41] Gopal, M. (2003) Digital Control and State Variable Methods. McGraw-Hill, New Delhi.

[42] Inooka, H., Obinata, G. and Takeshima, M. (1983) Design of a Controller Based on Series Expansion of Pulse Transfer Functions. Journal of Dynamic Systems, Measurement, and Control, 105, 204-207. http://dx.doi.org/10.1115/1.3140658

[43] Inooka, H., Watanbe, T. and Imai Y. (1988) Design of Digital Controller for Double-Loop Systems Based on Series Expansions. International Journal of Systems Science, 19, 15391546. http://dx.doi.org/10.1080/00207728808964055

[44] Su, J.T. and Liu, C.W. (2011) Proposed Digital Control Scheme for Improved Current Share of Multiphase DC/DC Converters. 8th IEEE International Conference on Power Electronics and ECCE Asia, Jeju, 30 May-3 June 2011, 1612-1617. http://dx.doi.org/10.1109/ICPE.2011.5944384

[45] Manual (2011) Magnetic Levitation Control Experiments. Feedback Instruments Limited, UK.

\section{Submit or recommend next manuscript to SCIRP and we will provide best service for you:}

Accepting pre-submission inquiries through Email, Facebook, LinkedIn, Twitter, etc.

A wide selection of journals (inclusive of 9 subjects, more than 200 journals)

Providing 24-hour high-quality service

User-friendly online submission system

Fair and swift peer-review system

Efficient typesetting and proofreading procedure

Display of the result of downloads and visits, as well as the number of cited articles

Maximum dissemination of your research work

Submit your manuscript at: http://papersubmission.scirp.org/

Or contact ica@scirp.org 